\title{
Patterns of Intimate Partner Violence Victimization from Adolescence to Young Adulthood in a Nationally Representative Sample
}

\author{
Carolyn Tucker Halpern, $\mathrm{PhD}^{1}$, Aubrey L. Spriggs, $\mathrm{MA}^{1}$, Sandra L. Martin, $\mathrm{PhD}^{1}$, and \\ Lawrence Kupper, $\mathrm{PhD}^{2}$ \\ ${ }^{1}$ Department of Maternal and Child Health, Gillings School of Global Public Health, University of \\ North Carolina at Chapel Hill \\ ${ }^{2}$ Department of Biostatistics, Gillings School of Global Public Health, University of North Carolina \\ at Chapel Hill
}

\section{Abstract}

Purpose-To determine the prevalence of patterns of intimate partner violence (IPV) victimization from adolescence to young adulthood, and document associations with selected sociodemographic and experiential factors.

\begin{abstract}
Methods-We used prospective data from the National Longitudinal Study of Adolescent Health to group 4,134 respondents reporting only opposite-sex romantic or sexual relationships in adolescence and young adulthood into four victimization patterns: no IPV victimization, adolescent-limited IPV victimization, young adult onset IPV victimization, and adolescent-young adult persistent IPV victimization.
\end{abstract}

Results-Forty percent of respondents reported physical or sexual victimization by young adulthood. Eight percent experienced IPV only in adolescence, $25 \%$ only in young adulthood, and 7\% showed persistent victimization. Female sex, Hispanic and non-Hispanic black race/ethnicity, an atypical family structure (something other than two biologic parents, step family, single parent), more romantic partners, experiencing childhood abuse, and early sexual debut (before age 16) were each associated with one or more patterns of victimization versus none. Number of romantic partners and early sexual debut were the most consistent predictors of violence, its timing of onset, and whether victimization persisted across developmental periods. These associations did not vary by biological sex.

Conclusions-Substantial numbers of young adults have experienced physical or sexual IPV victimization. More research is needed to understand the developmental and experiential mechanisms underlying timing of onset of victimization, whether victimization persists across time and relationships, and whether etiology and temporal patterns vary by type of violence. These additional distinctions would inform the timing, content, and targeting of violence prevention efforts.

(C) 2009 Society for Adolescent Medicine. Published by Elsevier Inc. All rights reserved.

Corresponding author: Carolyn Tucker Halpern, Department of Maternal \& Child Health, CB \# 8120, University of North Carolina at Chapel Hill, Chapel Hill, NC 27599-8120, carolyn_halpern@unc.edu PH: 919-966-4462, FAX: 919-966-6638.

Publisher's Disclaimer: This is a PDF file of an unedited manuscript that has been accepted for publication. As a service to our customers we are providing this early version of the manuscript. The manuscript will undergo copyediting, typesetting, and review of the resulting proof before it is published in its final citable form. Please note that during the production process errors may be discovered which could affect the content, and all legal disclaimers that apply to the journal pertain. 


\section{Keywords}

Adolescence; Intimate partner violence; longitudinal study; population-based study

Although a major public health issue, we know little about associations between adolescent and adult intimate partner violence (IPV). Most longitudinal work has examined the stability of violence over time within adolescent or adult relationships (1-3) or has been limited to adolescence (4). Analyses are often based on college students or other selected or homogeneous samples (e.g., (5-8)); therefore knowledge of longitudinal patterns in population-based samples is limited.

Longitudinal investigations of IPV typically focus on perpetration; the persistence of victimization from adolescence to adulthood is largely unexamined. Using the Wave III couples sub-sample of the National Longitudinal Study of Adolescent Health (Add Health), Lehrer (6) found that adolescent depression, physical victimization, and forced sex were associated with elevated risk of IPV in young adulthood. However, these analyses did not control for earlier relationship frequency (i.e., IPV opportunity), and did not examine males' victimization persistence. Additionally, because these couples are a purposive quota sample, generalizability to the broader population of young adults is unclear.

It is well-documented in other literatures (e.g., crime victimization) that some individuals are more likely to experience persistent victimization (9). The IPV literature, though limited by methodological weaknesses, also suggests victimization persistence for some individuals $(8,10-12)$. Reasons for victimization desistence or persistence are unknown. One might expect desistence if violence during adolescence stems from different causes than adult partner violence, for example, if adolescent IPV reflects "playful" behavior or poor impulse control that fades as teens mature $(13,14)$. Alternatively, because adolescent romances entail socialization, romantic "script" formation, and rehearsal for adult relationships, patterns precipitating adult violence may start in adolescence (13).

In the crime victimization literature, two explanations are proposed to explain repeated victimization: 1) population heterogeneity and 2) state dependence. According to the heterogeneity model, some individuals have time-stable personal characteristics (e.g., impulsivity, depression), relationship characteristics (e.g., selecting partners prone to aggression), lifestyle/activity patterns, or features of social contexts that increase the likelihood of victimization. Precocious experiences, such as early entry into romantic relationships, have been linked with IPV (15) and may be markers for other victimizationrelevant individual characteristics. State dependence models complement the heterogeneity argument by proposing that the experience of victimization changes aspects of the individual and/or their social context in ways that increase the likelihood of subsequent victimization $(16,17)$. For example, adolescent IPV victimization may have psychological consequences (e.g., depression) that increase vulnerability (5). Model integration suggests that persons who are adversely changed by victimization, and who have lifestyles or social contexts that treat violence as normative, would be more likely to suffer persistent victimization.

In a recent review of studies examining IPV in adolescent and young adult women, the authors concluded that evidence linking time-stable characteristics and contexts reflective of the heterogeneity model, such as socioeconomic status (SES), race/ethnicity, and family structure, to IPV is mixed. Positive associations between number of partners and IPV victimization are more consistently found, although not in all studies $(18,19)$.

Whether and when a risk factor should be considered as an element of the heterogeneity or state dependence models are not always clear. Depression is consistently related to physical 
and sexual victimization as both a precursor and a consequence $(6,19)$. Thus, pre-existing (i.e., pre-violence) depressive symptoms could reflect an individual characteristic that increases vulnerability, or could reflect a change in the individual resulting from an earlier victimization experience, or both. Depending on timing, processes from both models may be operative. Without longitudinal research with representative samples, conclusions about the sequence and developmental course of processes contributing to intimate violence victimization are limited.

Other victimization types such as childhood maltreatment are relevant to state dependence models. Childhood maltreatment has been linked to IPV during adolescence (8) and could heighten vulnerability to future victimization (20). Fang and Corso used Waves I and III Add Health data to document associations between childhood maltreatment and IPV perpetration and victimization in young adult relationships, and to test potential mediators (21). Results suggested youth violence perpetration is a mediator of the maltreatment/IPV perpetration link. However, linkage between maltreatment and IPV victimization was unclear, with only modest support for the hypothesis that "learned helplessness" (a changed feature of the individual) as a mediator. Although an important investigation of distal contributors to adult IPV, Fang and Corso did not examine associations between adolescent and adult victimization. Thus, the prevalence of persistence versus desistance of victimization, based on a representative sample, is unknown.

Depending on circumstances, early sexual debut, which has been linked cross-sectionally with IPV $(15,19)$, could fit state dependence or heterogeneity models. That is, debut may itself have been a victimization experience. Alternatively, early debut may be a marker for other individual characteristics, such as choices in number and types of partners $(19,22-25)$.

The timing of experiences in the life course and their persistence over time have important implications for health (26). Further, knowing the longitudinal patterns and prevalence of victimization experiences can inform investigations of explanatory models (27). We therefore use the nationally representative Add Health data to prospectively examine victimization onset timing and persistence between adolescence and young adulthood. We also examine associations with selected individual factors and earlier experiences identified in the literature as relevant to longitudinal patterns. It is not our purpose to comprehensively test the population heterogeneity and state dependence hypotheses. Rather, we provide population prevalence estimates and exploration of the utility of heterogeneity and state dependence models for persistent IPV victimization.

Our questions are:

1. What is the prevalence of adolescent versus young adult IPV victimization onset, and of persistent victimization in a nationally representative sample of young adults?

2. Are patterns of victimization associated with time stable characteristics (population heterogeneity hypothesis), or with earlier experiences (state dependence hypothesis) that could increase the likelihood of victimization? To address question 2, we compare any pattern of IPV victimization (defined below) versus none, persistence versus desistence in adulthood among those reporting adolescent victimization, and timing of victimization onset among those reporting adolescent or adult victimization but not both. 


\section{METHODS}

\section{Overview of Study Data}

Add Health was designed to examine determinants of health and health-related behaviors of adolescents in grades 7-12 in 1994-1995. A representative self-weighted core sample and several special samples were selected for in-home interviews (28). More than 21,000 Wave I in-home interviews were completed in 1995 (79\% of eligibles). Almost 15,000 respondents were re-interviewed at Wave II in 1996 (88\% of eligibles); in 2001, a Wave III interview was conducted with about 15,200 respondents who completed a Wave I in-home questionnaire (76\% of eligibles) (29). In-home questionnaires were administered via laptop computer; CASI was used for sensitive questions.

\section{Analysis Sample}

Eligibility for the analytic sample was based on information about romantic and sexual partnerships provided at Waves II and III. At Wave II, respondents reported up to six partnerships occurring since Wave I (approximately the past 18 months). At Wave III, respondents reported all partnerships occurring since summer 1995. Inclusion criteria for this analysis (cumulative effects on sample size in parentheses), were participating in all three Waves and having valid sampling weights $(\mathrm{n}=10,828)$, Wave II age less than 18 years $(n=8,281)$, reporting at least one partner before and after age $18(n=4,596)$, reporting exclusively opposite-sex romantic and sexual relationships at Waves II and III $(n=4,398)$, and having complete covariate data $(n=4,134)$. We limited our sample to those younger than age 18 at Wave II so that Wave II IPV reflects only adolescent experiences. Exclusion for same-sex involvement $(\mathrm{n}=198)$ was based on victimization differences between individuals reporting exclusively opposite-sex relationships versus other partnering histories $(18,30)$.

\section{Violence Measures}

Relationship-specific-Wave II and III responses were used to determine adolescent and adult victimization (questions were not asked at Wave I). Victimization questions were asked about multiple specific relationships. At Wave II, three items from the Conflict Tactics Scale 2 were queried (CTS2) (31); in some cases, item wording was slightly different. For each relationship reported, respondents were asked whether (no/yes) their partner had ever (a) threatened them with violence; (b) thrown something at them that could hurt them; (c) pushed or shoved them. Wave III items also came from the CTS2; the three victimization types queried at Wave II were combined into a single item at Wave III to accommodate assessment of other victimization types. For each relationship reported at Wave III, respondents reported how often (never to more than 20 times) during the past year (or the entire relationship if duration was less than one year) their partner had threatened them with violence, pushed or shoved them, or thrown something at them that could hurt; slapped, hit, or kicked them; insisted on or made them have sexual relations; or caused an injury like a sprain, bruise, or small cut because of a fight. For each relationship reported at Waves II and III, we constructed an "Any Violence" variable indicating a report of at least one incident of one or more of these acts.

Longitudinal Patterns-Our focus is the implication of adolescent physical victimization for all victimization assessed in young adulthood, as other work, albeit limited to a college sample, suggests that victimization of one type (physical or sexual) increases the risk of victimization of other types (8). To characterize patterns, we first classified relationships as adolescent or young adult. All relationships that began and ended before age 18 (whether reported at Wave II or Wave III) were classified as adolescent. Relationships reported at Wave III that started after age 18, were ongoing at the time of Wave III interview (when all respondents were age 18 or older), or ended after age 18 were classified as young adult. This 
scheme is the most accurate, as Wave III violence questions were asked with the time referent "in the past year" for relationships that were ongoing or lasted longer than a year. Respondents reporting no victimization in either adolescent or adult relationships were classified "no IPV;" those reporting victimization in adolescent but not adult relationships were classified "adolescent-limited;" those reporting victimization in adult but not adolescent relationships were classified "young adult onset;" and those reporting victimization in both adolescent and adult relationships were classified "adolescent-adult persistent."

\section{Correlates of victimization patterns}

As our primary goals are descriptive, we selected a small number of individual and experiential characteristics to explore the relevance of the population heterogeneity and state dependence models for longitudinal patterns of victimization.

\section{Individual Characteristics}

Age: Age is the date of birth subtracted from the date of the Wave III interview, rounded to the nearest whole number. Age was categorized in approximately two year intervals (18-19, $20-21,22-23,24-27)$ to allow for a possible nonlinear relationship with victimization.

Biological Sex: Biological sex is self-reported.

Race/Ethnicity: Race and ethnicity are based on respondent Wave I self-report, and categorized as non-Hispanic white, non-Hispanic black, Hispanic (any race), and nonHispanic other.

Family Structure: This reflects the adolescent's self-reported Wave I household roster. Categories include two biologic parents, step family, single parent, and other (e.g., living with grandparents).

Highest Parental Education: This is the highest level achieved by the respondent's resident father- or mother-figure, whichever was greater, as reported by the adolescent at Wave I. If there was only one parent figure in the household, their education level was used. Education was categorized as less than high school diploma, high school diploma/GED, some postsecondary, or bachelors or more.

Adolescent Depression: At Wave I, a 19-item modified version of the Center for Epidemiologic Studies - Depression scale was utilized to assess adolescent depressive symptoms in the past week. Respondents answered on a zero ("never") to three ("most or all of the time") scale; summary scores ranged from 0 to 56. A cutoff score of 22 for males and 24 for females maximizes sensitivity and specificity for major depressive disorder in the full 20 -item scale (32). We used proportionate cutoffs of 21 for males and 23 for females, similar to past studies (6).

\section{Partnership Characteristics}

Older partners in adolescence: Adolescent involvement with older partners is associated with risk behavior (33). We calculated the age gap between the respondent and each reported partner at Wave II using partner's age minus respondent's age. If the respondent reported any Wave II relationships with a partner who was more than two years older, that respondent was coded as having "older partners" in adolescence.

Number of partnerships in adolescence and young adulthood: This is the number of sexual or romantic partnerships active in the past 18 months reported by at the Wave II 
interview, plus the number of adolescent relationships reported at the Wave III interview. Number of partnerships in young adulthood is the number of partnerships reported at Wave III that qualified as young adult relationships as defined above.

Experiences-To examine the relevance of experiences as agents of change (i.e., state dependence hypothesis) we include childhood abuse and early sexual debut.

Childhood Abuse: Two Wave III items (whether before sixth grade a parent/caretaker slapped, hit, or kicked the respondent, or if a parent/caretaker sexually abused the respondent) were used to construct a dichotomous indicator (positive response to either or both items).

Early sexual debut: Early debut is self-reported age at first vaginal intercourse, categorized based on the distribution of debut age in the complete Wave III sample with weights $(\mathrm{n}=14,322)$; the lowest tertile (ages 10-15) is "early." Other analyses demonstrate the meaningfulness of this breakpoint $(34,35)$ for well-being indicators.

\section{Analysis}

Analyses were conducted using Stata version 9 (StataCorp LP, College Station, Texas), with corrections for complex survey design and weighting to yield nationally-representative estimates. Descriptive statistics were generated. Crude associations were tested using Chisquare. Interactions between respondent sex and all predictor variables were tested and found to be non-significant ( $p>0.20)$. We fit three multivariable logistic regression models. In Model 1, we tested whether predictors differentiated persons with any of our defined IPV victimization experiences from those with none. In Model 2, we tested whether predictors were related to desistence versus persistent victimization for persons with adolescent-onset victimization. In Model 3, we tested if predictors differentiated persons with adolescentversus young adult-onset victimization. This secondary analysis was reviewed by the Public Health-Nursing Institutional Review Board at the University of North Carolina at Chapel Hill and deemed exempt.

\section{RESULTS}

\section{Descriptive and Bivariate Results}

Table 1 presents characteristics for the analytic sample. Weighted percentages provide representative estimates of the adolescent U.S. population who report exclusively heterosexual relationships in both adolescence and young adulthood. Partner violence is prevalent: $8.3 \%$ experienced victimization only in adolescence, $24.8 \%$ experienced victimization only in young adulthood, and $7.2 \%$ experienced victimization in both adolescence and adulthood. Many more respondents report physical versus sexual victimization in childhood, adolescence and adulthood (not shown). Table 2 presents crude associations between predictors and longitudinal patterns of victimization. All predictors, except age, were significantly associated with one or more patterns.

\section{Adjusted Analyses}

Model 1: Any IPV victimization versus none-After adjustment for other variables, age remained non-significant, and parent education and adolescent depression were no longer associated with longitudinal patterns (see Table 3). Only sexual debut before age 16 was associated with elevated risk for all victimization patterns (versus no victimization), nearly tripling the odds of experiencing persistent victimization versus no violence. Other variables were associated with one or two patterns. Beyond sexual debut timing, persistent 
victimization (versus none) was associated with Black and Hispanic race/ethnicity, "other" family structure, and more than two partners in adolescence.

Models 2 and 3: Persistence and timing of victimization onset-We also examined predictors of victimization persistence versus desistence among respondents who reported victimization during adolescence, and timing of victimization onset among those who reported adolescent or adult victimization but not both (Table 4). In contrast to comparisons with "no violence," only two variables predicted persistent victimization versus desistance. These were early sexual debut, also significant in Model 1, and having two or more partners in young adulthood. Timing of onset was predicted by "other" family structure, early sexual debut, and multiple partners in adolescence and young adulthood. We also tested Models 1- 3 limiting adult victimization to physical (non-sexual) violence; this more narrow victimization specification did not substantively change our results.

\section{Discussion}

Using a nationally representative, longitudinal sample of males and females, we examined partner violence victimization onset timing and persistence between adolescence and young adulthood. We examined how patterns vary by individual characteristics and experiential factors relevant to the heterogeneity and state dependence models. Cumulatively $40 \%$ of respondents (36\% of males and $44 \%$ of females) reported onset of physical or sexual victimization by young adulthood. These population-based estimates are substantially lower than those reported for more selected populations such as female college students $(8,36)$, for whom lifetime prevalence estimates range between 70 and $80 \%$. In present analyses, similar proportions of individuals with adolescent onset of victimization showed persistent and adolescent-limited patterns. Although the most common victimization pattern was young adult onset, over $7 \%$ of the sample, or a population estimate of 552,055 persons, showed persistent victimization from adolescence to adulthood.

Findings from adjusted models support both the population heterogeneity and state dependence models. Time-stable personal are associated with victimization, but as Vezina and Hebert noted, associations are scattered and vary across pattern comparisons (19). There are more consistent associations with numbers of partners (19). Examination of the types of partners individuals select over time is important for future research. Although present analyses suggest sex differences in certain victimization patterns (versus no IPV), with females at greater risk, the absence of interactions between sex and other predictors suggests the processes underlying these associations do not differ for males and females.

Of characteristics and experiences investigated here, only early sexual debut and numbers of partners $(37,38)$ reliably predict persistence (persistent versus no violence in Model 1, persistence versus desistance in Model 2). To our knowledge, we are the first to examine prospectively the association between early sexual debut and IPV victimization patterns over time, and to demonstrate the significance of early sexual debut for persistent victimization even when partner age and the number of partners (i.e., exposure opportunity) are controlled. We do not have information about the qualities of sexual debut (e.g., voluntary or coerced, pleasurable or not, regretted afterward or not). Therefore we cannot determine whether the association between age at debut and persistent victimization reflects stable characteristics of the individual or their relationships (i.e., heterogeneity model), or whether the debut experience changed the individual in ways that increase vulnerability (i.e., state dependence model).

Limited information also precludes testing our hypothesis that person-changing experiences within contexts where violence is normative may be more powerful contributors to 
persistent victimization. However, present analyses do not suggest an additive effect (i.e., abuse and debut are not both significant in the same model), and other work (39) does not support an interaction between childhood abuse and witnessing violent crime during adolescence as a predictor of the continuation of victimization into adulthood among adolescent IPV victims.

Our research has limitations. Partner violence is measured by acts, without social context or emotional responses, so we cannot identify defensive behavior. Second, partner violence perpetration and victimization are often linked (40), and ideally our analysis would examine longitudinal patterns of both. However, because perpetration was not assessed in adolescence in Add Health, our analysis is limited to victimization. Third, because of missing end dates (5\% of relationships), we could not always determine if a relationship was adolescent limited, and therefore when IPV first occurred. Because Add Health does not necessarily capture all lifetime partnerships and all types of violence, some respondents may be misclassified by victimization pattern. Finally, we caution that, fundamentally, the perpetrator is responsible for their violent behavior, and our findings should not be interpreted as placing blame with the victims of violence.

\section{Conclusions}

Substantial numbers of adolescents are persistently victimized, suggesting developmental linkages between adolescent and adult romantic relationships. To answer broad questions about the timing and persistence of IPV victimization we aggregated across violence types in our analyses. It would be useful in future longitudinal work to disaggregate victimization types to examine their specific patterns over time, and to investigate whether contributors to persistent IPV victimization vary by type of violence and social context. There is suggestive evidence of the specificity of some risk factors based on cross-sectional data (19). It would also be useful to look at co-victimization within a given relationship. Sexual education that includes "relationship modules" that systematically expose individual throughout adolescence to prosocial "romantic scripts" and addresses appropriate methods of conflict resolution are needed. Better understanding of the processes determining how individuals respond to opportunities for positive change would further inform the timing and targeting of violence prevention efforts.

\section{Acknowledgments}

Ms. Spriggs' time on this project was supported by the Carolina Population Center, NICHD NRSA predoctoral traineeship, grant number NIH-NICHD T32-HD07168.

This research uses data from Add Health, a program project designed by J. Richard Udry, Peter S. Bearman, and Kathleen Mullan Harris, and funded by a grant P01-HD31921 from the Eunice Kennedy Shriver National Institute of Child Health and Human Development, with cooperative funding from 17 other agencies. Special acknowledgment is due Ronald R. Rindfuss and Barbara Entwisle for assistance in the original design. Persons interested in obtaining data files from Add Health should contact Add Health, Carolina Population Center, 123 W. Franklin Street, Chapel Hill, NC 27516-2524 (addhealth@unc.edu). No direct support was received from grant P01-HD31921 for this analysis.

\section{References}

1. O'Leary K, Smith SA. A dyadic longitudinal model of adolescent dating aggression. Journal of Clinical Child and Adolescent Psychology. 2003; 32(3):314-327. [PubMed: 12881021]

2. Caetano R, Field CA, Ramisetty-Mikler S, McGrath C. The 5-year course of intimate partner violence among White, Black, and Hispanic couples in the United States. Journal of Interpersonal Violence. 2005; 20(9):1039-1057. [PubMed: 16051726] 
3. Feld, SL.; Straus, MA. Escalation and desistance from wife assault in marriage. In: Straus, M.; Gelles, R., editors. Physical violence in American families: Risk factors and adaptations to violence in 8,145 families. New Brunswick, NJ: Transaction; 1990. p. 489-505.

4. Foshee VA, Benefield T, Suchindran C, Ennett ST, Bauman KE, Karriker-Jaffe KJ, et al. The development of four types of adolescent dating abuse and selected demographic correlates. Journal of Research on Adolescence. 2008 (In Press).

5. Himelein MJ. Risk factors for sexual victimization in dating: A longitudinal study of college women. Psychology of Women Quarterly. 1995; 19(1):31-48.

6. Lehrer JA, Buka S, Gortmaker S, Shrier LA. Depressive symptomatology as a predictor of exposure to intimate partner violence among US female adolescents and young adults. Archives of Pediatrics \& Adolescent Medicine. 2006; 160(3):270-276. [PubMed: 16520446]

7. Rickert VI, Wiemann CM, Vaughan RD, White JW. Rates and risk factors for sexual violence among an ethnically diverse sample of adolescents. Archives of Pediatrics \& Adolescent Medicine. 2004; 158(12):1132-1139. [PubMed: 15583097]

8. Smith PH, White JW, Holland LJ. A longitudinal perspective on dating violence among adolescent and college-age women. American Journal of Public Health. 2003; 93(7):1104-1109. [PubMed: 12835193]

9. Winkel FW, Blaauw E, Sheridan L, Baldry AC. Repeat criminal victimization and vulnerability for coping failure: A prospective examination of a potential risk factor. Psychology, Crime \& Law. 2003; 9(1):87.

10. Graves KN, Sechrist SM, White JW, Paradise MJ. Intimate partner violence perpetrated by college women within the context of a history of victimization. Psychology of Women Quarterly. 2005; 29(3):278-289.

11. Humphrey JA, White JW. Women's vulnerability to sexual assault from adolescence to young adulthood. Journal of Adolescent Health. 2000; 27(6):419-424. [PubMed: 11090744]

12. Testa M, VanZile-Tamsen C, Livingston JA. Prospective prediction of women's sexual victimization by intimate and nonintimate male perpetrators. Journal of Consulting and Clinical Psychology. 2007; 75(1):52-60. [PubMed: 17295563]

13. Henton J, Cate R, Koval J, Lloyd S, Christopher S. Romance and violence in dating relationships. Journal of Family Issues. 1983; 4(3):467-482.

14. Foshee VA, Bauman KE, Linder F, Rice J, Wilcher R. Typologies of adolescent dating violence Identifying typologies of adolescent dating violence perpetration. Journal of Interpersonal Violence. 2007; 22(5):498-519. [PubMed: 17429020]

15. Silverman JG, Raj A, Mucci LA, Hathaway JE. Dating violence against adolescent girls and associated substance use, unhealthy weight control, sexual risk behavior, pregnancy, and suicidality. Jama-Journal of the American Medical Association. 2001; 286(5):572-579.

16. Nagin D, Paternoster R. Population heterogeneity and state dependence: State of the evidence and directions for future research. Journal of Quantitative Criminology. 2000; 16(2):117-144.

17. Ousey G, Wilcox P, Brummel S. De’ja` vu all over again: Investigating temporal continuity of adolescent victimization. Journal of Quantitative Criminology. 2008; 24:307-335.

18. Halpern CT, Oslak SG, Young ML, Martin SL, Kupper LL. Partner violence among adolescents in opposite-sex romantic relationships: Findings from the National Longitudinal Study of Adolescent Health. American Journal of Public Health. 2001; 91(10):1679-1685. [PubMed: 11574335]

19. Vezina J, Hebert M. Risk factors for victimization in romantic relationships of young women - A review of empirical studies and implications for prevention. Trauma Violence \& Abuse. 2007; $8(1): 33-66$.

20. Widom CS. Posttraumatic stress disorder in abused and neglected children grown up. American Journal of Psychiatry. 1999; 156(8):1223-1229. [PubMed: 10450264]

21. Fang X, Corso PS. Child maltreatment, youth violence, and intimate partner violence: developmental relationships. Am J Prev Med. 2007; 33(4):281-290. [PubMed: 17888854]

22. Krahe B. Sexual aggression among adolescents - Prevalence and predictors in a German sample. Psychology of Women Quarterly. 1998; 22(4):537-554. 
23. O'Keefe M, Treister L. Victims of dating violence among high school students: Are the predictors different for males and females? Violence Against Women. 1998; 4(2):195-223. [PubMed: 12295441]

24. Synovitz LB, Byrne TJ. Antecedents of sexual victimization: Factors discriminating victims from nonvictims. Journal of American College Health. 1998; 46(4):151-158. [PubMed: 9519576]

25. Petersen, AC.; Taylor, B. The biological approach to adolescence: Biological change and psychological adaptation. In: Adelson, J., editor. Handbook of adolescent psychology. New York, NY: Wiley; 1980. p. 117-155.

26. Elder, JGH.; Shanahan, M. The life course and human development. In: Damon, W.; Lerner, R., editors. Handbook of Child Psychology, Volume 1, Theoretical Models of Human Development. 6th ed.. New York: Wiley and Stone; 2006. p. 665-715.

27. Shanahan M, Erickson L, Bauer D. One hundred years of knowing: The changing science of adolescence, 1904 and 2004. Journal of Research on Adolescence. 2005; 15(4):383-394.

28. Harris, KM.; Florey, F.; Tabor, J.; Bearman, PS.; Jones, J.; Udry, JR. Chapel Hill, NC: Carolina Population Center, University of North Carolina at Chapel Hill; 2003. The National Longitudinal Study of Adolescent Health: Research Design [WWW document].

29. Chantala, K.; Kalsbeek, WD.; Andraca, E. Non-Response in Wave III of the Add Health Study. Chapel Hill, NC: Carolina Population Center; 2004.

30. Halpern CT, Young ML, Waller MW, Martin SL, Kupper LL. Prevalence of partner violence in same-sex romantic and sexual relationships in a National Sample of Adolescents. Journal of Adolescent Health. 2004; 35(2):124-131. [PubMed: 15261641]

31. Straus MA, Hamby SL, Boney-McCoy S, Sugarman DB. The revised Conflict Tactics Scales (CTS2): Development and preliminary psychometric data. Journal of Family Issues. 1996; 17(3): 283-316.

32. Roberts R, Lewinsohn P, Seeley J. Screening for adolescent depression: a comparison of depression scales. Journal of the American Academy of Child and Adolescent Psychiatry. 1991; 30(1):58-66. [PubMed: 2005065]

33. Halpern CT, Kaestle CE, Hallfors DD. Perceived physical maturity, age of romantic partner, and adolescent risk behavior. Prevention Science. 2007; 8(1):1-10. [PubMed: 16972191]

34. Spriggs AL, Halpern CT. Timing of sexual debut and initiation of postsecondary education by early adulthood. Perspect Sex Reprod Health. 2008; 40(3):152-161. [PubMed: 18803797]

35. Spriggs AL, Halpern CT. Sexual debut timing and depressive symptoms in emerging adulthood. Journal of Youth and Adolescence. 2008; 37(9):1085-1096. [PubMed: 19802319]

36. Humphrey J, White J. Women's vulnerability to sexual assault from adolescence to young adulthood. Journal of Adolescent Health. 2000; 27(6):419-424. [PubMed: 11090744]

37. Santelli J, Brener N, Lowry R, Bhatt A, Zabin L. Multiple sexual partners among U.S. adolescents and young adults. Family Planning Perspectives. 1998; 30(6):271-275. [PubMed: 9859017]

38. O'Donnell L, O'Donnell C, Stueve A. Early sexual initiation and subsequent sex-related risks among urban minority youth: The Reach for Health Study Family Planning Perspectives. 2001; 33(6):268-275.

39. Spriggs AL, Halpern CT, Martin SL. Continuity of adolescent and early adult partner violence victimization: Association with witnessing crime in adolescence. Journal of Epidemiology and Community Health. In press.

40. Gray HM, Foshee V. Adolescent dating violence - Differences between one-sided and mutually violent profiles. Journal of Interpersonal Violence. 1997; 12(1):126-141. 
Table 1

Weighted Estimates of Sample Characteristics of Individuals: Young Adults Aged 18-26 Years, National Longitudinal Study of Adolescent Health, United States, $2001(\mathrm{n}=4,134)$

\begin{tabular}{|c|c|c|}
\hline & $\mathbf{n}$ & $\% a$ \\
\hline \multicolumn{3}{|c|}{ Sociodemographic characteristics } \\
\hline \multicolumn{3}{|l|}{ Biological Sex } \\
\hline Male & 1749 & 46.0 \\
\hline Female & 2385 & 54.0 \\
\hline \multicolumn{3}{|l|}{ Wave III Age, y } \\
\hline $18-19$ & 519 & 15.8 \\
\hline $20-21$ & 1702 & 45.2 \\
\hline $22-23$ & 1913 & 39.1 \\
\hline \multicolumn{3}{|l|}{ Race/ethnicity } \\
\hline Non-Hispanic White & 2501 & 72.8 \\
\hline Non-Hispanic Black & 797 & 13.2 \\
\hline Hispanic & 594 & 10.4 \\
\hline Non-Hispanic Other & 242 & 3.6 \\
\hline \multicolumn{3}{|l|}{ Wave I Family structure } \\
\hline Both biologic & 2317 & 56.8 \\
\hline Step family & 736 & 18.1 \\
\hline Single parent & 976 & 22.6 \\
\hline Other & 105 & 2.5 \\
\hline \multicolumn{3}{|l|}{ Parent education } \\
\hline$<$ HS/GED & 443 & 10.2 \\
\hline HS/GED & 1200 & 30.4 \\
\hline Some postsecondary & 895 & 23.1 \\
\hline College graduate & 1596 & 36.4 \\
\hline \multicolumn{3}{|c|}{ Individual characteristics and experiences } \\
\hline Wave I Depression & 377 & 8.6 \\
\hline Early sexual debut & 1539 & 38.6 \\
\hline Childhood abuse & 1197 & 28.0 \\
\hline \multicolumn{3}{|l|}{ Partnership characteristics } \\
\hline Wave II Older Partner & 751 & 17.1 \\
\hline \multicolumn{3}{|l|}{ Adolescent \# partners } \\
\hline One & 2191 & 51.2 \\
\hline Two or more & 1943 & 48.8 \\
\hline \multicolumn{3}{|l|}{ Young adult \# partners } \\
\hline One & 1973 & 49.6 \\
\hline Two or more & 2161 & 50.4 \\
\hline \multicolumn{3}{|l|}{ Longitudinal IPV patterns } \\
\hline No IPV & 2503 & 59.7 \\
\hline Adolescent-limited & 314 & 8.3 \\
\hline
\end{tabular}




\begin{tabular}{lrr}
\hline & \multicolumn{1}{c}{$\mathbf{n}$} & $\boldsymbol{\%}^{\boldsymbol{a}}$ \\
\cline { 2 - 3 } Young adult onset & 1025 & 24.8 \\
Adolescent-young adult persistent & 292 & 7.2 \\
\hline
\end{tabular}

${ }^{a}$ All percentages are adjusted for sampling probability; listed sample sizes are unweighted. 


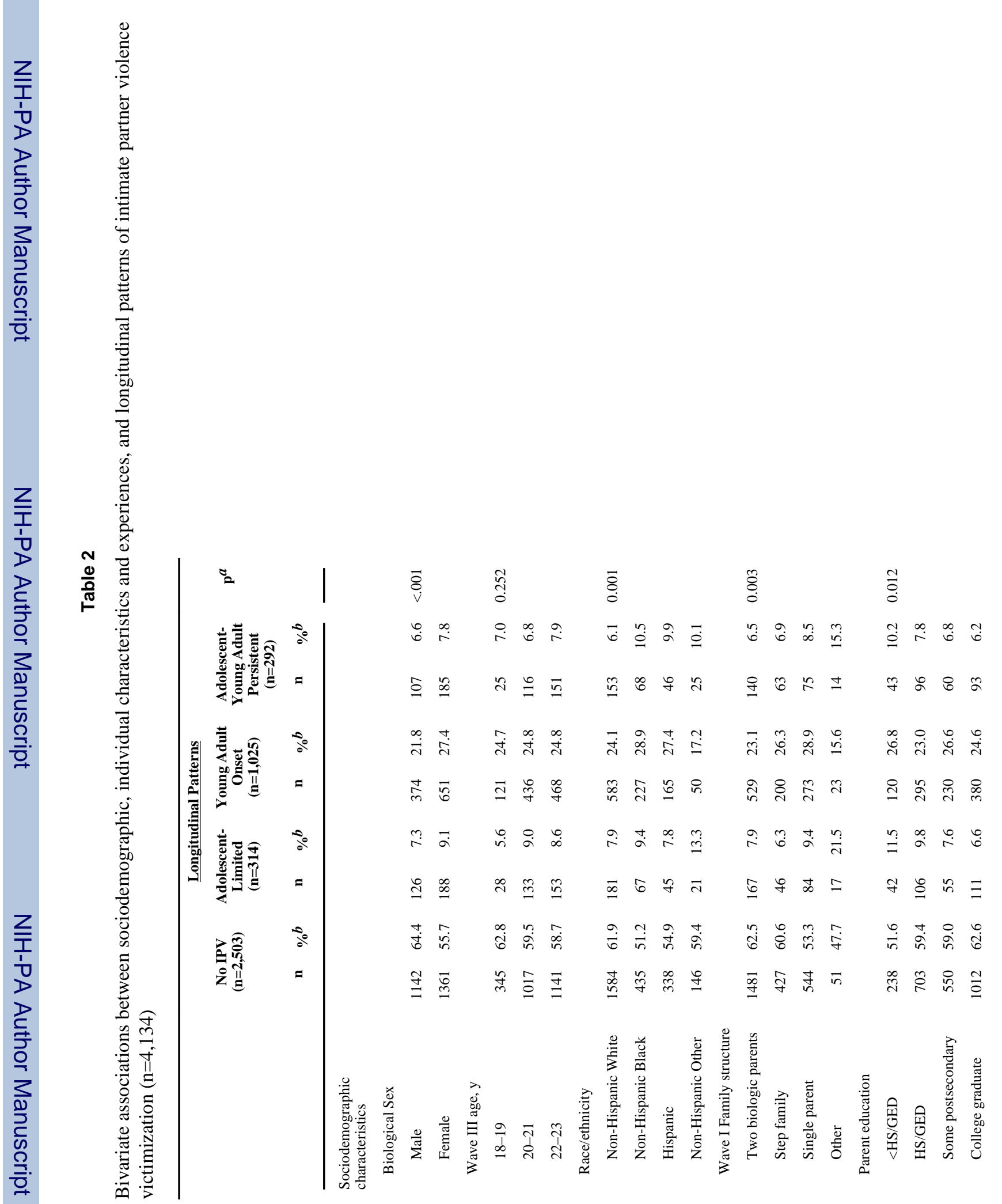


Halpern et al.

Page 14

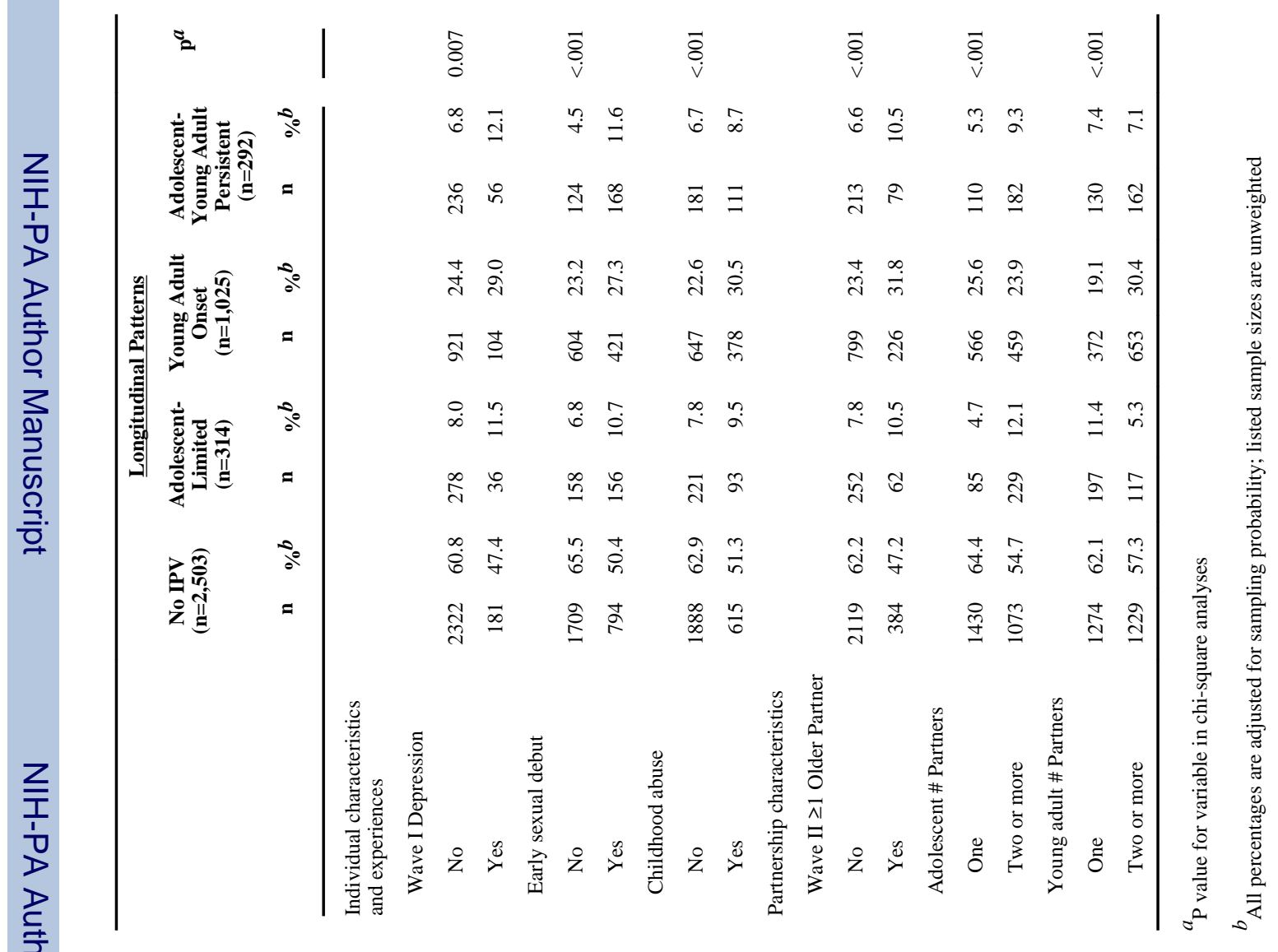

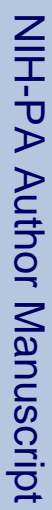

J Adolesc Health. Author manuscript; available in PMC 2011 July 18. 
Table 3

Multinomial logistic regression analysis of relationships between sociodemographic, individual characteristics and experiences, and longitudinal patterns of intimate partner violence victimization $(n=4,134)$

\begin{tabular}{|c|c|c|c|c|}
\hline & \multicolumn{3}{|c|}{ Model 1: Any IPV victimization vs. none } & \multirow[b]{2}{*}{$\mathbf{p}^{a}$} \\
\hline & $\begin{array}{l}\text { Adolescent-Limited } \\
\text { vs. No IPV } \\
\text { AOR }(95 \% \text { CI })\end{array}$ & $\begin{array}{l}\text { Young Adult } \\
\text { Onset } \\
\text { vs. No IPV } \\
\text { AOR }(95 \% \text { CI })\end{array}$ & $\begin{array}{l}\text { Adolescent-Adult } \\
\text { Persistent } \\
\text { vs. No IPV } \\
\text { AOR }(95 \% \text { CI })\end{array}$ & \\
\hline \multicolumn{5}{|l|}{$\begin{array}{l}\text { Sociodemographic } \\
\text { characteristics }\end{array}$} \\
\hline Biological Sex (Female) & $1.40(1.03-1.90)$ & $1.32(1.09-1.60)$ & $1.23(0.81-1.87)$ & 0.014 \\
\hline Wave III age & $1.10(0.97-1.25)$ & $0.97(0.89-1.06)$ & $1.01(0.88-1.17)$ & 0.316 \\
\hline \multicolumn{5}{|l|}{ Race/ethnicity } \\
\hline Non-Hispanic White & Referent & Referent & Referent & 0.002 \\
\hline Non-Hispanic Black & $1.17(0.77-1.79)$ & $1.30(1.01-1.81)$ & $1.76(1.07-2.92)$ & \\
\hline Hispanic & $0.94(0.56-1.60)$ & $1.30(0.99-1.70)$ & $1.65(1.01-2.70)$ & \\
\hline Non-Hispanic Other & $1.98(0.93-4.21)$ & $0.77(0.41-1.42)$ & $1.90(0.92-3.91)$ & \\
\hline \multicolumn{5}{|l|}{ Wave I Family structure } \\
\hline Both biologic & Referent & Referent & Referent & 0.020 \\
\hline Step family & $0.68(0.43-1.09)$ & $1.02(0.79-1.31)$ & $0.87(0.57-1.32)$ & \\
\hline Single parent & $1.08(0.73-1.60)$ & $1.24(0.98-1.57)$ & $1.05(0.65-1.70)$ & \\
\hline Other & $2.85(1.34-6.06)$ & $0.80(0.41-1.57)$ & $2.41(1.11-5.26)$ & \\
\hline \multicolumn{5}{|l|}{ Parent education } \\
\hline College graduate & Referent & Referent & Referent & 0.411 \\
\hline$<$ HS/GED & $1.76(1.05-2.94)$ & $1.06(0.77-1.45)$ & $1.34(0.78-2.32)$ & \\
\hline HS/GED & $1.32(0.90-1.92)$ & $0.87(0.68-1.12)$ & $1.04(0.68-1.60)$ & \\
\hline Some postsecondary & $1.13(0.69-1.84)$ & $1.03(0.79-1.34)$ & $1.02(0.64-1.64)$ & \\
\hline \multicolumn{5}{|l|}{$\begin{array}{l}\text { Individual characteristics } \\
\text { and experiences }\end{array}$} \\
\hline Wave I Depression & $1.28(0.78-2.10)$ & $1.31(0.92-1.87)$ & $1.71(1.09-2.67)$ & 0.135 \\
\hline Early sexual debut & $1.69(1.22-2.34)$ & $1.40(1.14-1.72)$ & $2.83(1.95-4.13)$ & $<.001$ \\
\hline Childhood abuse & $1.32(0.95-1.84)$ & $1.62(1.33-1.95)$ & $1.40(0.99-1.98)$ & $<.001$ \\
\hline \multicolumn{5}{|l|}{ Partnership characteristics } \\
\hline Wave II Older Partner & $1.13(0.79-1.63)$ & $1.40(1.09-1.81)$ & $1.34(0.95-1.88)$ & 0.037 \\
\hline $2+$ adolescent partners & $2.67(1.86-3.81)$ & $1.05(0.87-1.28)$ & $1.75(1.27-2.41)$ & $<.001$ \\
\hline $2+$ young adult partners & $0.57(0.41-0.80)$ & $1.81(1.46-2.26)$ & $1.22(0.88-1.69)$ & $<.001$ \\
\hline
\end{tabular}

Note. AOR = adjusted odds ratio $\mathrm{CI}=$ confidence interval

${ }^{a} \mathrm{P}$ value for Wald chi-square test. 
Table 4

Logistic regression analysis of factors associated with victimization persistence vs. desistence and timing of victimization onset

\begin{tabular}{|c|c|c|c|c|}
\hline & \multicolumn{2}{|l|}{ Model 2: } & \multicolumn{2}{|l|}{ Model 3: } \\
\hline & \multicolumn{2}{|c|}{ Persistence vs. Desistence $^{a}$} & \multicolumn{2}{|c|}{ Timing of IPV Onset $b$} \\
\hline & $\begin{array}{l}\text { Persistent vs. } \\
\text { Adolescent-limited } \\
\text { AOR }(95 \% \text { CI })\end{array}$ & $\mathrm{p}^{c}$ & $\begin{array}{l}\text { Adolescent onset vs. } \\
\text { Young adult onset } \\
\text { AOR (95\% CI) }\end{array}$ & $\mathrm{p}^{c}$ \\
\hline \multicolumn{5}{|l|}{$\begin{array}{l}\text { Sociodemographic } \\
\text { characteristics }\end{array}$} \\
\hline Biological Sex (Female) & $0.86(0.51-1.43)$ & 0.553 & $1.02(0.76-1.38)$ & 0.884 \\
\hline Wave III age & $0.86(0.68-1.07)$ & 0.171 & $1.09(0.98-1.21)$ & 0.112 \\
\hline \multicolumn{5}{|l|}{ Race/ethnicity } \\
\hline Non-Hispanic White & Referent & 0.363 & Referent & 0.051 \\
\hline Non-Hispanic Black & $1.45(0.80-2.65)$ & & $1.08(0.77-1.52)$ & \\
\hline Hispanic & $1.87(0.86-4.05)$ & & $0.90(0.57-1.42)$ & \\
\hline Non-Hispanic Other & $1.36(0.55-3.37)$ & & $2.28(1.22-4.28)$ & \\
\hline \multicolumn{5}{|l|}{ Wave I Family structure } \\
\hline Both biologic & Referent & 0.798 & Referent & 0.014 \\
\hline Step family & $1.29(0.74-2.24)$ & & $0.79(0.55-1.14)$ & \\
\hline Single parent & $0.99(0.61-1.61)$ & & $0.85(0.61-1.20)$ & \\
\hline Other & $0.90(0.35-2.31)$ & & $3.23(1.40-7.47)$ & \\
\hline \multicolumn{5}{|l|}{ Parent education } \\
\hline College graduate & Referent & 0.753 & Referent & 0.174 \\
\hline$<$ HS/GED & $0.74(0.36-1.52)$ & & $1.46(0.88-2.43)$ & \\
\hline HS/GED & $0.82(0.47-1.45)$ & & $1.40(1.02-1.91)$ & \\
\hline Some postsecondary & $0.95(0.49-1.85)$ & & $1.15(0.75-1.75)$ & \\
\hline \multicolumn{5}{|l|}{$\begin{array}{l}\text { Individual characteristics and } \\
\text { experiences }\end{array}$} \\
\hline Wave I Depression & $1.53(0.83-2.82)$ & 0.169 & $1.08(0.74-1.57)$ & 0.700 \\
\hline Early sexual debut & $1.74(1.04-2.91)$ & 0.034 & $1.53(1.14-2.06)$ & 0.005 \\
\hline Childhood abuse & $1.03(0.66-1.60)$ & 0.905 & $0.86(0.64-1.15)$ & 0.298 \\
\hline \multicolumn{5}{|l|}{ Partnership characteristics } \\
\hline Wave II Older Partner & $1.16(0.71-1.90)$ & 0.542 & $0.91(0.65-1.27)$ & 0.565 \\
\hline $2+$ adolescent partners & $0.65(0.41-1.04)$ & 0.074 & $2.00(1.50-2.68)$ & $<.001$ \\
\hline $2+$ young adult partners & $2.25(1.39-3.63)$ & 0.001 & $0.45(0.32-0.64)$ & $<.001$ \\
\hline
\end{tabular}

Note $\mathrm{AOR}=$ adjusted odds ratio $\mathrm{CI}=$ confidence interval.

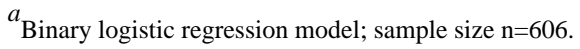

${ }^{b}$ Binary logistic regression model; sample size $\mathrm{n}=1,631$.

${ }^{c}$ P value for Wald chi-square test. 